\title{
A Ruptured Pseudoaneurysm of an Anomalous Gastroduodenal Artery: A Rare Presentation
}

\author{
Anish Shrestha ${ }^{1}$, Anisha Shrestha ${ }^{2}$, Bikal Ghimire ${ }^{3,4}$ \\ 1. Department of Gastrointestinal and General Surgery, Institute of Medicine, Kathmandu, NPL 2. Department of \\ Gastrointestinal and General Surgery, Maharajgunj Medical Campus, Institute of Medicine, Tribhuvan University, \\ Kathmandu, NPL 3. Department of Surgery, Institute of Medicine, Tribhuvan University Teaching Hospital, \\ Kathmandu, NPL 4. Department of Surgery, Tribhuvan University Teaching Hospital, Kathmandu, NPL
}

Corresponding author: Bikal Ghimire, bikalghimire@gmail.com

\begin{abstract}
Gastroduodenal artery (GDA) anomalies are a rare entity. Rupture of such anomalies can present with a diagnostic challenge. In this report, we describe a case of ruptured pseudoaneurysm of an anomalous GDA arising directly from the aorta presenting with recurrent abdominal pain and anemia. The diagnosis was made on computed tomography scan which showed acute retroperitoneal fluid collection. Further angiographic intervention highlighted the anomalous GDA arising directly from the aorta.
\end{abstract}

Categories: Radiology, General Surgery, Anatomy

Keywords: pseudoaneurysm, gda, vaa, gastroduodenal artery, visceral artery pseudoaneurysm

\section{Introduction}

Celiac trunk is the artery of the foregut, arising from the abdominal aorta at the level of twelfth thoracic and the first lumbar vertebral level. It courses approximately 1.5 to $2 \mathrm{~cm}$ forward horizontally before dividing into three branches: left gastric, common hepatic, and splenic arteries. The gastroduodenal artery (GDA) arises as a terminal branch of the common hepatic artery along with the proper hepatic artery. A cadaveric study done by Lipshutz reported the GDA to originate from the common hepatic artery in $92.3 \%$ of the cases [1]. Another study conducted in 31 cadavers showed the GDA to originate from the common hepatic artery in $100 \%$ of the cases [2]. This emphasizes the variation in the origin of the GDA as a rare entity. There have been reports of the GDA arising from the celiac trunk or superior mesenteric artery [1,3,4], but seldom has there been any report of the GDA arising directly from the abdominal aorta. Rupture of such anomalous GDA can present with signs and symptoms different from a typical rupture.

Review began 05/02/2021 Review ended 05/07/2021 Published 05/08/2021

\section{๑) Copyright 2021}

Shrestha et al. This is an open access article distributed under the terms of the Creative Commons Attribution License CC-BY 4.0., which permits unrestricted use, distribution, and reproduction in any medium, provided the original author and source are credited.
A true aneurysm of an artery involves all the three layers of the vessel wall while a pseudoaneurysm lacks intimal and medial layers. Visceral artery aneurysm (VAA)/splanchnic artery aneurysm refers to intraabdominal aneurysms excluding the aortoiliac axis. Some autopsy studies have suggested that splanchnic artery aneurysms occur more frequently than abdominal aortic artery aneurysms [5]; however, most of them are clinically silent [6-8]. These aneurysms are very important to recognize because the repair of a ruptured VAA has three to four-fold increased mortality and morbidity compared to an unruptured VAA [9].

Anatomical variations of visceral arteries and their aneurysms are usually diagnosed by computed tomography (CT) and/or angiography. Here, we describe the case of a pseudoaneurysm rupture presenting with abdominal mass due to retroperitoneal hematoma and abdominal pain.

\section{Case Presentation}

A 45-year-old female presented to the Emergency Department with a history of on and off abdominal pain for one year that evolved to continuous pain for one month along with multiple episodes of vomiting containing food particles without a history of hematemesis. She also complained of shortness of breath. On further inquiry, she gave a history of water brash on and off but denied a history of trauma or diarrhea. With a hemoglobin level of $6.4 \mathrm{~g} / \mathrm{dL}$, she had been transfused with two units of blood at a different hospital where contrast-enhanced CT scan had been performed which reported hemorrhagic collection in the upper retroperitoneal region with contrast extravasation from the GDA, with separate origin of the GDA from the aorta (Figures 1, 2, 3). Her hemoglobin at this time was $9.3 \mathrm{~g} / \mathrm{dL}$. Palpation of her abdomen revealed a $10 \times 10$ $\mathrm{cm}$, non-pulsatile, tender mass in the upper quadrant. 


\section{Cureus}

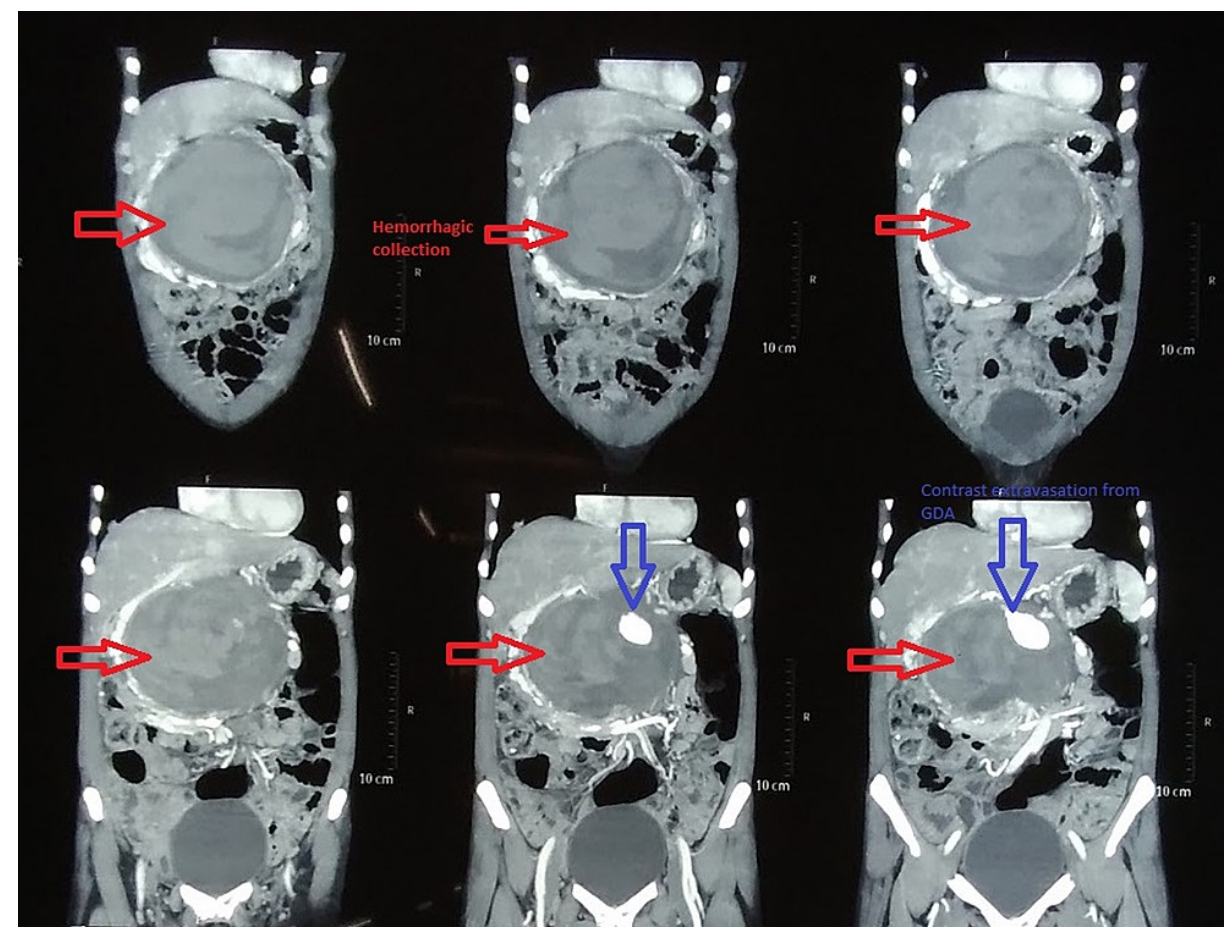

FIGURE 1: CT: Coronal sections showing retroperitoneal hemorrhagic collection.

CT: computed tomography; GDA: gastroduodenal artery

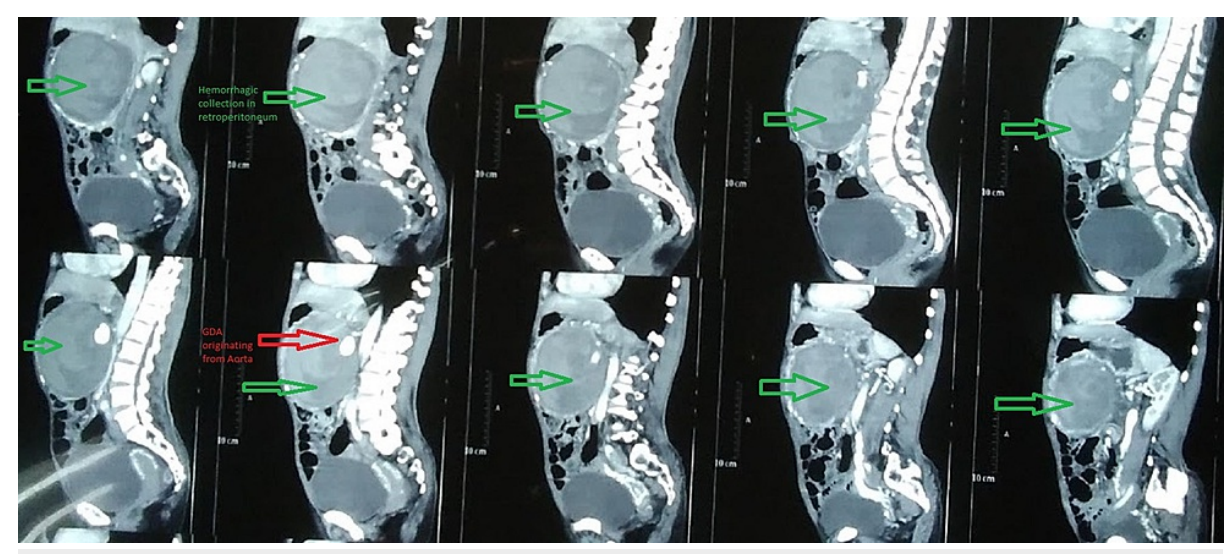

FIGURE 2: CT: Sagittal sections showing anomalous origin of the GDA from the aorta.

CT: computed tomography; GDA: gastroduodenal artery 


\section{Cureus}

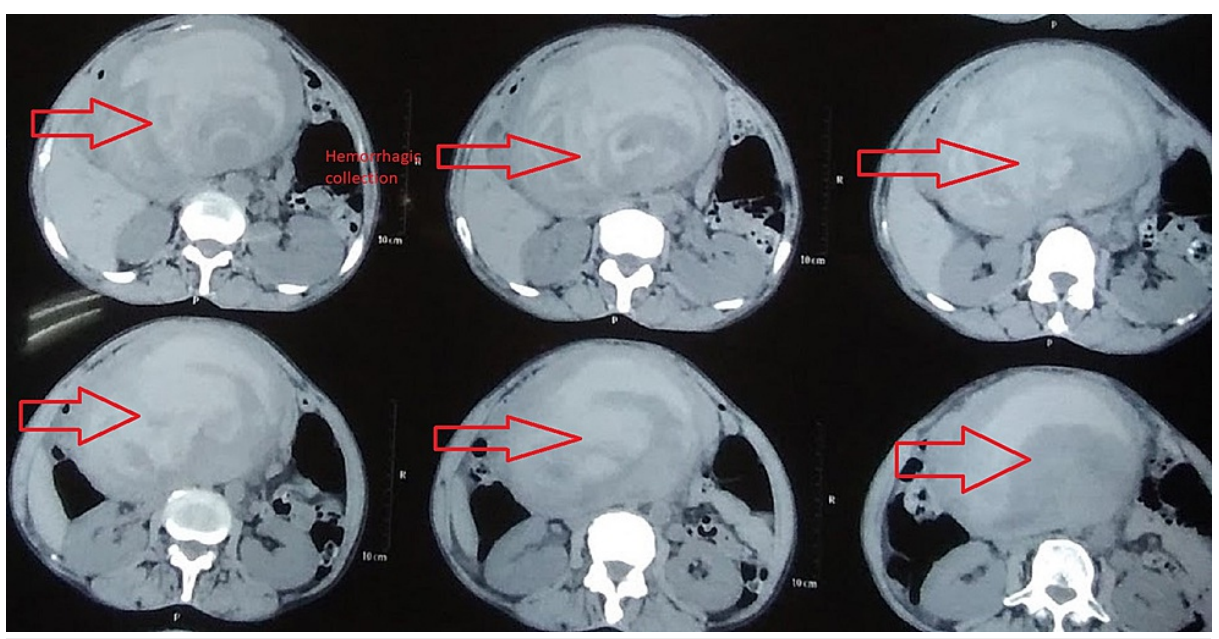

FIGURE 3: CT: Transverse sections showing retroperitoneal blood collection.

CT: computed tomography

The patient underwent coil embolization of the GDA via a transfemoral approach. Using a 5-Fr Cobra catheter, three coils of size $4 \times 8 \mathrm{~mm}, 5 \times 5 \mathrm{~mm}$, and $4 \times 8 \mathrm{~mm}$ were delivered. There was evidence of pseudoaneurysm of the GDA arising directly from the aorta with additional finding of the left hepatic artery originating from the left gastric artery. After embolization, her hemoglobin was checked every eight hours which remained static.

\section{Discussion}

VAAs can be a true or a pseudoaneurysm. True aneurysm results from vessel wall abnormality such as atherosclerosis, cystic medial necrosis, and Marfan's syndrome, whereas pseudoaneurysms usually result from inflammatory or traumatic conditions [5].

The incidence of VAA in autopsy ranges from $0.098 \%$ to $10.4 \%$ with an average of $1 \%[6,7]$. The prevalence of VAA in clinical practice is reported to be $0.1 \%$ to $2 \%$ [8]. This difference signifies that most VAAs are clinically silent. About $60 \%$ of splanchnic aneurysms involve the splenic artery, $20 \%$ the hepatic artery, $5 \%$ the superior mesenteric artery, $4 \%$ the smaller branches of the celiac artery (gastric, pancreaticoduodenal, gastroepiploic), and another $4 \%$ the celiac artery [10]. Jejunal, ileal, and colic arteries represent $3 \%$ of the total number of cases [7]. The GDA accounts for $1.5 \%$ of all VAAs, most of which are pseudoaneurysms. Despite its rarity, it has a high-risk rupture of about $75 \%$ [11].

GDA pseudoaneurysm has mostly been described as a complication of chronic pancreatitis. Rarely, it has been described in association with peptic ulcer disease [12]. Our patient did not give a history suggestive of chronic pancreatitis but had a history consistent with symptoms of acid peptic disease.

Clinical presentation of GDA aneurysm rupture is varied, hence leading to a delay in the diagnosis. Gastrointestinal hemorrhage secondary to rupture of the aneurysm is the most common clinical presentation (52\%), abdominal pain occurs in $46 \%$ of the cases, while $7.5 \%$ remain asymptomatic [11]. Pulsatile abdominal mass along with bruit also suggests the presence of an aneurysm, but its absence does not rule it out. GDA pseudoaneurysm can manifest with symptoms of obstructive jaundice and pancreatitis because of extrahepatic compression of the common bile duct and pancreatic duct by mass effect [13]. In addition, such a mass can cause compressive symptoms manifesting as vomiting. The same was noted in our case as well.

Although spontaneous thrombosis of pseudoaneurysm has occasionally been reported, the consecutive treatment is associated with mortality as high as 90\% [14]. Endovascular intervention and open surgery are the two treatment approaches for VAAs. The choice between the two usually depends upon the hemodynamic stability of the patient as well as anatomical feasibility for endovascular repair [11,14]. In case of failure of endovascular repair, one can always resort to open surgery. In this patient, the resulting retroperitoneal hematoma from the ruptured pseudoaneurysm seemed to have had a tamponade effect preventing further extravasation of blood. It was probably due to this reason that her vitals remained stable. Therefore, we opted for endovascular repair.

Treatment of aneurysms in an emergency setting, either using an open or endovascular approach, is 
associated with a much higher mortality and morbidity rate than those performed in an elective setting [9]. Usually, the elective treatment is done for VAAs of size $>2 \mathrm{~cm}$ [7]. However, its treatment should not rely completely on its size but should also depend on factors such as rate of increase in aneurysm size and location.

\section{Conclusions}

Clinical presentations of rare entities possess a diagnostic dilemma. Early and prompt diagnosis of such conditions can save lives. We recommend contrast-enhanced CT abdomen scans as a diagnostic aid in such situations.

\section{Additional Information \\ Disclosures}

Human subjects: Consent was obtained or waived by all participants in this study. Conflicts of interest: In compliance with the ICMJE uniform disclosure form, all authors declare the following: Payment/services info: All authors have declared that no financial support was received from any organization for the submitted work. Financial relationships: All authors have declared that they have no financial relationships at present or within the previous three years with any organizations that might have an interest in the submitted work. Other relationships: All authors have declared that there are no other relationships or activities that could appear to have influenced the submitted work.

\section{References}

1. Lipshutz B: A composite study of the coeliac axis artery . Ann Surg. 1917, 65:159-69. 10.1097/00000658191702000-00006

2. Joleya M, Suryavanshi S, Sharma D: Variations in origin of gastroduodenal artery: a cadaveric study . IJSS J Surg. 2016, 2:

3. Michels NA: The hepatic, cystic and retroduodenal arteries and their relations to the biliary ducts with samples of the entire celiacal blood supply. Ann Surg. 1951, 133:503-24. 10.1097/00000658-19510400000009

4. Michels NA: Collateral arterial pathways to the liver after ligation of the hepatic artery and removal of the celiac axis. Cancer. 1953, 6:708-24. 10.1002/1097-0142(195307)6:4<708::aid-cncr2820060411>3.0.co;2-a

5. Pasha SF, Gloviczki P, Stanson AW, Kamath PS: Splanchnic artery aneurysms. Mayo Clin Proc. 2007, 82:4729. $10.4065 / 82.4 .472$

6. Sessa C, Tinelli G, Porcu P, Aubert A, Thony F, Magne JL: Treatment of visceral artery aneurysms: description of a retrospective series of 42 aneurysms in 34 patients. Ann Vasc Surg. 2004, 18:695-703. 10.1007/s10016-004-0112-8

7. Panayiotopoulos YP, Assadourian R, Taylor PR: Aneurysms of the visceral and renal arteries . Ann R Coll Surg Engl. 1996, 78:412-9.

8. Pitton MB, Dappa E, Jungmann F, et al.: Visceral artery aneurysms: incidence, management, and outcome analysis in a tertiary care center over one decade. Eur Radiol. 2015, 25:2004-14. 10.1007/s00330-015-3599-1

9. Zuhaili B, Molnar RG, Malhotra NG: The endovascular management of a 3.5-cm gastroduodenal artery aneurysm presenting with gastritis and recurrent pancreatitis. Avicenna J Med. 2017, 7:130-2. 10.4103/ajm.AJM 317

10. Chapman BM, Bolton JS, Gioe SM, Conway WC: Gastroduodenal artery pseudoaneurysm causing obstructive jaundice. Ochsner J. 2021, 21:104-7. 10.31486/toj.19.0110

11. Habib N, Hassan S, Abdou R, et al.: Gastroduodenal artery aneurysm, diagnosis, clinical presentation and management: a concise review. Ann Surg Innov Res. 2013, 7:4. 10.1186/1750-1164-7-4

12. Minhas PS, Virdi JK: Ruptured gastroduodenal artery aneursym - rare but deadly complication of duodenal ulcers. Am J Respir Crit Care Med. 2017, 195:5798.

13. Khan AA, Hafeez M: Gastroduodenal artery pseudoaneurysm and aberrant right hepatic artery . J Coll Physicians Surg Pak. 2017, 27:S71-3.

14. Gupta V, Irrinki S, Sakaray YR, et al.: Treatment strategies for bleeding from gastroduodenal artery pseudoaneurysms complicating the course of chronic pancreatitis-a case series of 10 patients. Indian J Gastroenterol. 2018, 37:457-63. 10.1007/s12664-018-0897-y 